NASA/TM-2000-210346

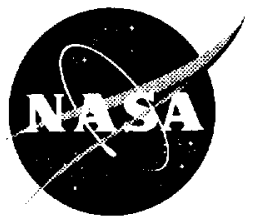

\title{
Active Combustion Control for Aircraft Gas Turbine Engines
}

John C. DeLaat, Kevin J. Breisacher, Joseph R. Saus, and Daniel E. Paxson Glenn Research Center, Cleveland, Ohio

Prepared for the

36th Joint Propulsion Conference and Exhibition

sponsored by the American Institute of Aeronautics and Astronautics

Huntsville, Alabama, July 17-19, 2000

National Aeronautics and

Space Administration

Glenn Research Center 
Available from

NASA Center for Aerospace Information

7121 Standard Drive

Hanover, MD 21076

Price Code: A03

National Technical Information Service 5285 Port Royal Road Springfield, VA 22100

Price Code: A03 
AIAA 2000-3500

\title{
ACTIVE COMBUSTION CONTROL FOR AIRCRAFT GAS TURBINE ENGINES
}

\author{
John C. DeLaat, Kevin J. Breisacher, Joseph R. Saus, Daniel E. Paxson \\ NASA Glenn Research Center at Lewis Field \\ 21000 Brookpark Road \\ Cleveland, Ohio 44135
}

\begin{abstract}
Lean-burning combustors are susceptible to combustion instabilities. Additionally, due to nonuniformities in the fuel-air mixing and in the combustion process, there typically exist hot areas in the combustor exit plane. These hot areas limit the operating temperature at the turbine inlet and thus constrain performance and efficiency. Finally, it is necessary to optimize the fuel-air ratio and flame temperature throughout the combustor to minimize the production of pollutants. In recent years, there has been considerable activity addressing Active Combustion Control. NASA Glenn Research Center's Active Combustion Control Technology effort aims to demonstrate active control in a realistic environment relevant to aircraft engines. Analysis and experiments are tied to aircraft gas turbine combustors. Considerable progress has been shown in demonstrating technologies for Combustion Instability Control, Pattern Factor Control, and Emissions Minimizing Control. Future plans are to advance the maturity of active combustion control technology to eventual demonstration in an engine environment.
\end{abstract}

\section{Introduction}

Future aircraft engines must provide ultra-low emissions and high efficiency at low cost while maintaining the reliability and operability of present day engines. The demands for increased performance and decreased emissions have resulted in advanced combustor designs that are critically dependent on effective fuel-air mixing and lean operation. However,

\footnotetext{
Copyright $\bigcirc 2000$ by the American Institute of Aeronautics and Astronautics, Inc. No copyright is asserted in the United States under Title 17. U.S. Code. The U.S. Government has a royalty-free license to exercise all rights under the copyright claimed herein for Goveremmental Purposes. All other rights are reserved by the copyright owner.
}

lean-burning low-emissions combustors are particularly susceptible to combustion instabilities. These instabilities are typically caused by the interaction of the fluctuating heat release of the combustion process with naturally occurring acoustic resonances. ${ }^{1}$ These interactions can produce large pressure oscillations within the combustor and can reduce component life and potentially lead to premature mechanical failures.

Additionally, due to non-uniformities in the fuelair mixing and in the combustion process, there typically exist hot areas in the combustor exit plane entering the turbine. These hot streaks limit the operating temperature at the turbine inlet and thus constrain performance and efficiency. In addition, these hot streaks can be zones of increased formation of oxides of nitrogen (NOx). The non-uniformities in combustor exit temperature are described by a parameter called pattern factor. Elimination of the hot streaks, that is, a reduction in pattern factor, can provide greater turbine life, can effectively increase the maximum combustor operating temperature and thus increase engine efficiency and performance, and can also contribute to emissions reduction.

Finally, the combustor flame temperature is largely a function of the combustion zone fuel-air mixture ratio. In order to minimize the formation of carbon monoxide ( $\mathrm{CO}$ ) and unburned hydrocarbons (UHC's), it is desirable to maintain a mixture ratio near stoichiometric. Unfortunately, mixture ratios near stoichiometric give high flame temperatures that lead to increased NOx formation. In order to minimize $\mathrm{CO}$, $\mathrm{UHC}$, and NOx production, tight control over the fuelair ratio is required.

Advanced design and analysis tools such as the National Combustion Code $e^{2,3}$ and physics-based combustion dynamics models ${ }^{4.5 .6}$ can guide the design and development process for modern low-emissions, high-performance gas turbine combustors. However, 
dynamic modeling is not as mature as steady-state CFD modeling. This limits the use of dynamic models during the design phase. As a result, passive approaches to dealing with combustor dynamic problems are often applied late in the combustor development process. This tends to be expensive. Active Combustion Control (ACC), which provides feedback-based control of the fuel injection, the fuel-air mixing process, and the staging of fuel sources, can provide an alternative approach to achieving acceptable combustor dynamic behavior, and thus can provide flexibility (additional margin) during the combustor design process.

In recent years, there has been considerable activity addressing ACC. Government, academia, and industry research efforts, through analysis and the use of laboratory combustors, have shown the considerable potential for active control. ${ }^{7,8,9.10,11,12,13}$ The NASA Glenn ACC Technology effort aims to demonstrate active control in a realistic environment relevant to aircraft engines by providing experiments tied to aircraft gas turbine combustors. The intent is to allow the maturity of active combustion control technology to advance to eventual demonstration in an engine environment.

NASA Glenn's effort in ACC includes three related efforts: Combustion Instability Control, Burner Pattern Factor Control, and Emission Minimizing Control. Each of these efforts is described in this paper. Significant results are given as well as references to where more detailed results can be found. Finally, the remaining challenges to $\mathrm{ACC}$ are given along with recommendations for future work.

\section{Combustion Instability Dynamics and Control}

Combustion instabilities are usually the result of interactions between the combustion process and the acoustic fields within the combustor. In-phase coupling of the heat addition and combustor acoustics can result in self-excited thermo-acoustic instabilities (Figure 1).

The control measures taken in order to damp or eliminate these instabilities include passive and active techniques. ${ }^{1.14}$ Passive control techniques include hardware and design modifications that do not have a dynamic component. Examples of passive techniques include modifications to the fuel delivery system and/or the combustor hardware in order to reduce the variation in the heat release process or increase acoustic damping. Active control techniques depend on a dynamic or time-varying hardware component (actuator). Typically, the intent of an active

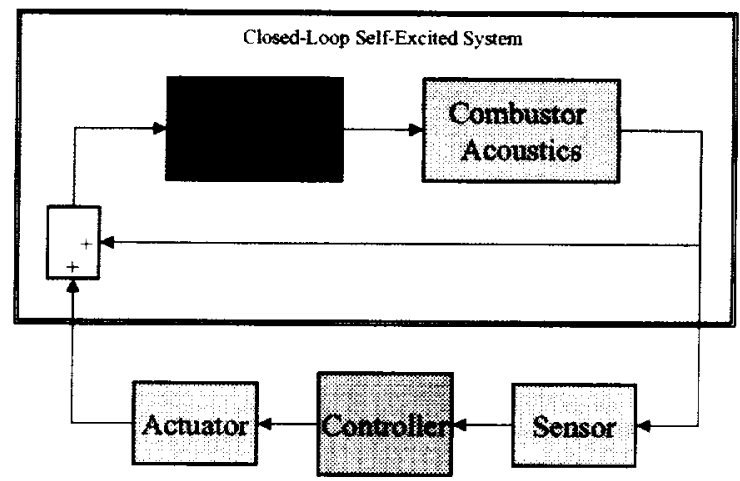

\section{Figure 1 - Combustion Thermo-Acoustic Instability with Active control}

combustion instability control approach is to perturb the combustion process in a fashion that disrupts the coupling between the combustion process and the combustor acoustics (see Fig. 1). The approach most often considered for aircraft gas turbine engines is dynamic modulation of the fuel flow since it has the most direct influence.

\section{Combustion Dynamic Modeling}

Stability Analysis Models It is not currently possible to predict a priori the stability of a gas turbine combustor. This inability is due largely to computational and physical modeling limitations. The computational requirements to compute a sufficiently long time history (hundreds of acoustic wave cycles) with a 3D (for tangential modes) multi-nozzle engine geometry over the operational envelope of the engine remains beyond the capabilities of most institutions. The physical modeling limitations are due to the wide variety of physical mechanisms that can lead to instabilities, and to the intractability of two phenomena of particular importance: 1) the evolution of vortical structures in a combusting, acoustically active environment; and 2) the dynamics of the two-phase fuel flow.

For the foreseeable future, stability analysis will have to rely on codes of varying fidelity and computational requirements. One and two dimensional time domain and three dimensional acoustic codes (particularly when energy release models are anchored with flametube data) can be used to identify regions of low stability margin in the operating envelope. AYT Corp. and NASA Glenn are using a 2D "thin-annular" code anchored with flametube data to make predictions of the stability characteristics of upcoming full scale low emissions combustor sector tests. 
Multi-dimensional CFD codes can be used to model problem areas with a fidelity that the lower dimensional models lack. NASA Glenn has a grant with Pennsylvania State University to use Large Eddy Simulation (LES) techniques to develop a fuel nozzle response model to calculate nozzle resonances. ${ }^{6}$ The resulting nozzle response information can be utilized along with less detailed calculations of the frequency response of other combustor sub-components to ensure that there are no matches in sub-component resonances. The fuel injector that Penn State is analyzing in this effort is the same engine injector being used for the Empirical Combustion Instability Control effort described later in this paper.

Control Development Models A significant amount of combustor dynamic modeling will most likely be required to implement active control schemes on practical systems. The one- and two- dimensional time domain codes will play an important role in assessing the feasibility of various control schemes.

Simplified, 1-D, Quasi-1-D, and Sectored-1-D combustor dynamic models ${ }^{15}$ are being developed by NASA Glenn to aid control system development and testing. These approaches utilize the one-dimensional (or quasi-one-dimensional), Navier-Stokes equations as their basis. In addition to mass, momentum, and energy equations, there are also one or more species transport equations. Associated with these are relatively simple reaction and heat release equations. The governing equations of motion are solved numerically using a very simple, second-order MacCormack scheme. Artificial viscosity is added in order to damp non-physical oscillations in vicinities of strong spatial gradients such as those brought about by the combustion process. The numerical scheme and associated artificial viscosity were chosen because of the computational speed which they afford.

If the combustor geometry is such that there are abrupt changes in cross section, a sectored approach is used. Here, the combustor is approximated by dividing it into a finite number of one-dimensional (constant area) sectors as shown in Figure 2. Within each sector, the equations of motion and species transport are integrated numerically. Across the sectors, mass and energy are conserved, and momentum loss is prescribed using appropriately compatible boundary conditions that account for the area change.

The resulting simulation and associated boundary conditions essentially represent a one-dimensional, multi-block technique. This approach has been used to successfully reproduce self-excited instabilities that have been observed in several experimental rigs.

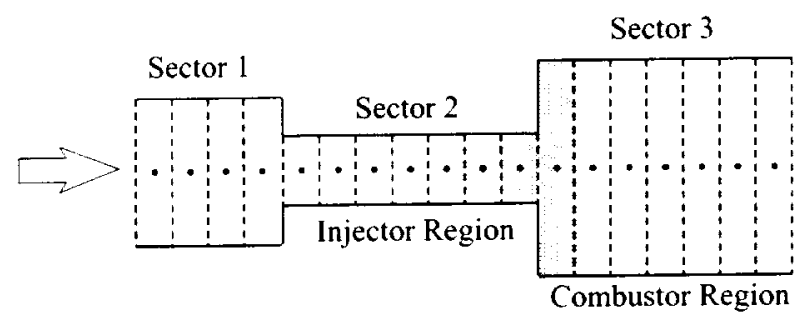

Figure 2 - Lean Premix Combustor Schematic

Figure 3 shows the geometrical layout of one such experiment that was simulated using the sectoredone-dimensional approach. This is a lean, premixprevaporize (LPP) combustor design that exhibited instabilities at certain operating points. When the simulation was run under the same conditions, selfexcited, unstable operation commenced, and eventually reached limit cycle behavior. The computed peak-topeak amplitude of the pressure fluctuations at the location of a pressure transducer was approximately $7.7 \%$ of the mean. This is close to the $8 \%$ value measured experimentally. Contour plots of nondimensional pressure and velocity fluctuations (deviations from the time-mean values) are presented in Figure 4 for approximately 2 oscillatory cycles. These are presented in order to show the mode shape of the instability. It would appear that this limit cycle is primarily the quarter wave mode of the combustor section proper.

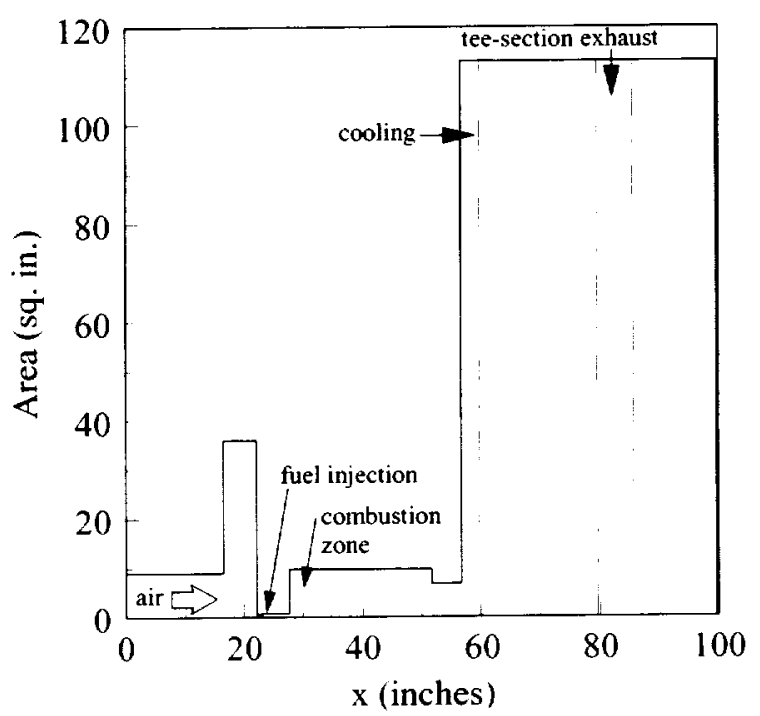

Figure 3 - Combustion Rig Geometry 

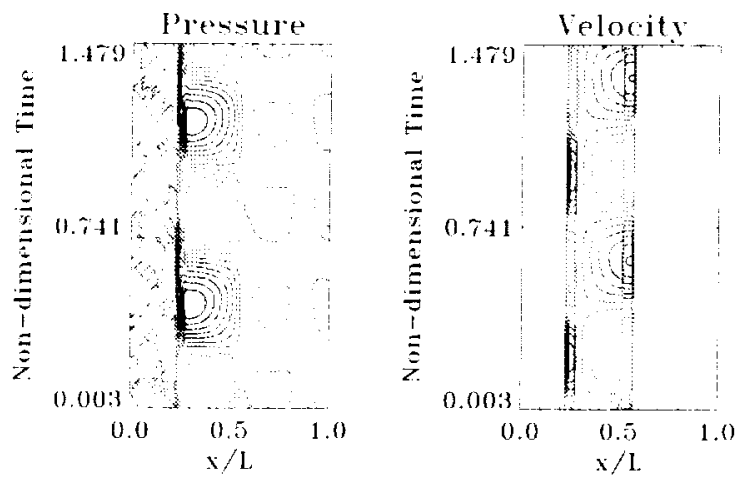

Figure 4 - Contours of Non-dimensional Pressure and Velocity Fluctuations for 2 Cycles of the Limit Cycle

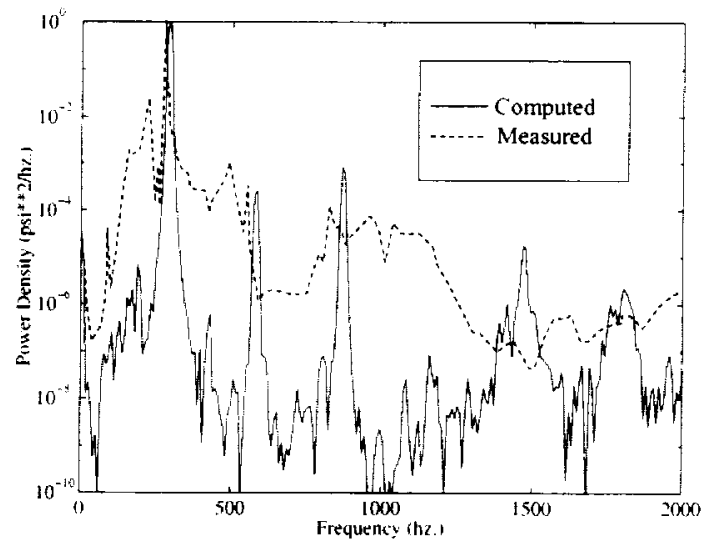

Figure 5 - Power Spectral Density Distribution of Pressure for $\mathrm{x}=\mathbf{4 2 . 1}$ Inches During Limit Cycle

Measured and computed Power Spectral Density distributions (PSD) of pressure at the experimental transducer location are presented in Figure 5. Critical similarities are the frequency and power density associated with the instability. For reference, the measured dominant frequency was $275 \mathrm{~Hz}$. The computed value was $291 \mathrm{~Hz}$. Although differing significantly in magnitude, the presence of higher frequency modes can also be seen at approximately 570 and $850 \mathrm{~Hz}$. in both the computed and measured spectra. This suggests that the subtle acoustic properties of the rig are reasonably reproduced in the simulation.

The sectored-one-dimensional, numerical, reacting flow solver technique is relatively simple and fast. The combustor rig simulation just described took 188 seconds of CPU time to simulate 0.116 seconds of real time running on a Sun Ultra 2 Workstation. Yet the technique is also reasonably accurate. These features make it useful for characterization and testing of control strategies. Furthermore, modeling and implementation of control actuation, such as fuel flow perturbations, are straightforward in the 1-D CFD framework. Further details on the approach are given in Ref. 15.

The 2-D "thin annular" codes mentioned earlier" may play an important role in analyzing nozzle-tonozzle interaction for both passive and active approaches to controlling tangential mode instabilities. AYT Corporation, NASA Glenn and the Department of Energy have begun a collaboration to address these issues.

\section{Combustion Instability Control}

The lack of detailed combustor dynamic models makes a rigorous control development methodology (an exact reasoning approach) difficult to pursue. On the other hand, control development methods that primarily treat the combustor as an input/output relationship (an approximate reasoning approach) may be feasible, but may be unable to take into account some of the important dynamic relationships in the combustor physics.

To address this spectrum of potential control approaches, the NASA Combustion Instability Control element has efforts covering three different control development methods. First, research into neuralnetwork-based control is being conducted using a relatively complex lean premix-prevaporize (LPP) combustor rig in order to demonstrate a near-term approximate reasoning approach. Second, as a medium-term, more exact reasoning approach, an empirical control development method using non-linear system identification and control techniques is being pursued for a single-nozzle combustor rig with many real combustor features. And third, research is being conducted for physics-based control approaches using a simple, tube-type laboratory combustor in order to allow the eventual demonstration of an exact reasoning approach on a more real combustor.

Neural Combustion Instability Control The neural-network-based control approach is seeking to develop a neural controller capable of adequately attenuating thermo-acoustic instabilities observed in an LPP combustor flame-tube. The control action is to occur through the modulation of the primary fuel supply to the combustor. Figure 6 shows the block diagram for the neural controller approach. The "plant" actually consists of three parts: the combustor, the fuel actuation dynamics, and the sensor dynamics. The 


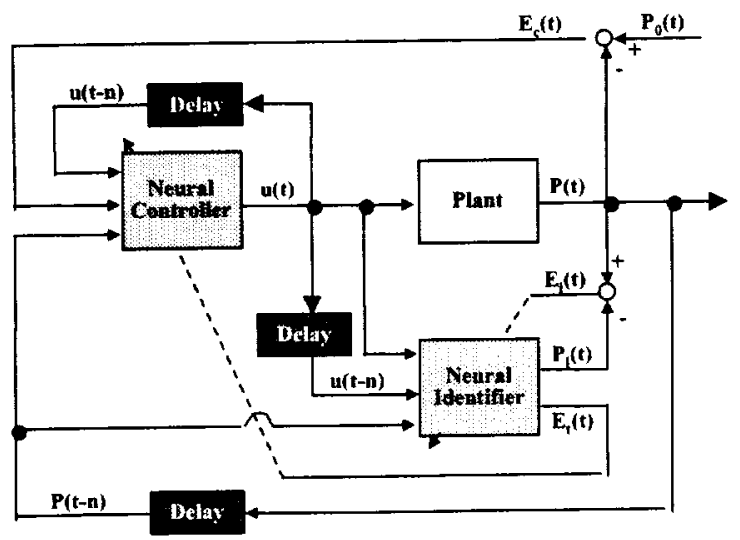

Figure 6 - Neural Combustion Instability Control Approach

neural identifier learns the dynamics of the plant and provides the desired output value for the neural controller. The neural identifier and neural controller networks are both of a Bama Optimized Recurrent Neural Network (BORN) type. ${ }^{16}$

Initially, the neural control approach is being developed through software simulation. The quasi-1-D model of an LPP combustor discussed earlier is being used to train the networks and will serve as a way to measure the neural controller's performance. The model will be run at five different operating points between low and full power, with an input signal, $u$, that spans prescribed ranges of frequency and amplitude. This input and the pressure output from the plant, $P$, will be recorded in a data file. Half of this data will be used to train the neural identifier off-line; the other half will be used for its testing.

Once trained, the neural identifier replaces the plant during training of the neural controller. The neural identifier pressure output is compared to a priori background pressure measurements (i.e., measurements taken when no combustion is taking place). The difference is backpropagated through the input layer of the neural identifier to determine what the input should have been in order to minimize the error. This ideal input is the desired value for the output of the neural controller. The error between the desired and the controller's actual output is then used in a conventional backpropagation sense to train the neural controller.

Once proof of concept has been demonstrated in a simulation environment, NASA plans to implement the trained controller in real time and demonstrate the neural control with a NASA-owned LPP flame-tube combustor rig.

Empirical Combustion Instability Control The goal of the empirical combustion instability control effort is to develop a control for a realistic combustion instability. The approach consists of developing a combustor rig which replicates an engine combustion instability, conducting system identification in order to develop reduced-order models of the rig, and then using the reduced-order models for control development. The sample problem selected for this effort is a combustion instability that was observed during the development of a high-performance aircraft gas-turbine engine. The frequency of the observed instability at a mid-power operating condition was $525 \mathrm{~Hz}$, and the magnitude of the pressure oscillations was sufficient to cause unacceptable vibratory stresses in the turbine.

The empirical combustion instability control effort has designed, fabricated, and tested an enginescale, liquid-fueled single-nozzle research combustor rig. The rig successfully replicates the engine instability and operates at engine pressure and temperature conditions. The single-nozzle combustor rig has many of the complexities of a real engine combustor including an actual engine fuel nozzle and swirler, dilution cooling, and an effusion-cooled liner (Figure 7). The research combustor rig was developed in partnership with Pratt \& Whitney and United Technologies Research Center (UTRC). Experimental testing with the combustor rig is taking place at UTRC.

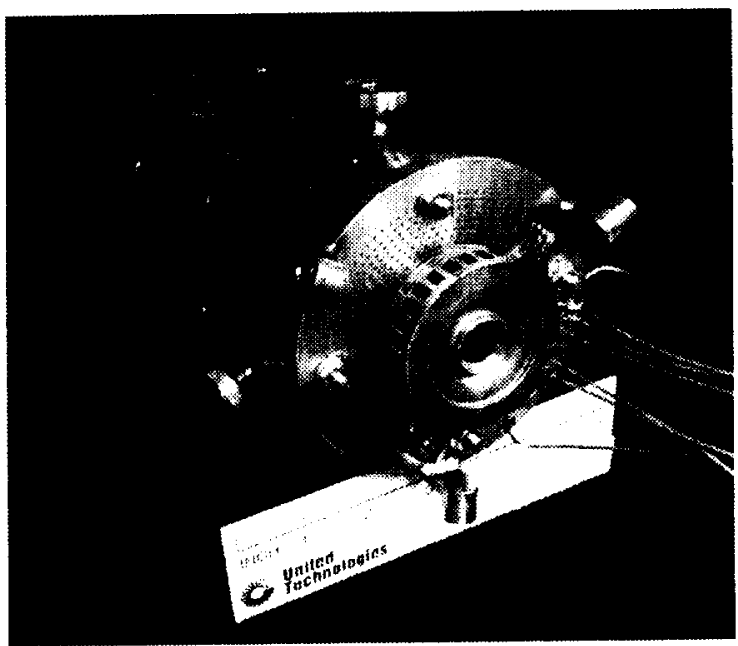

Figure 7 - Combustor Rig for Empirical Combustion Instability Control Research (Photograph by United Technologies Research Center) 


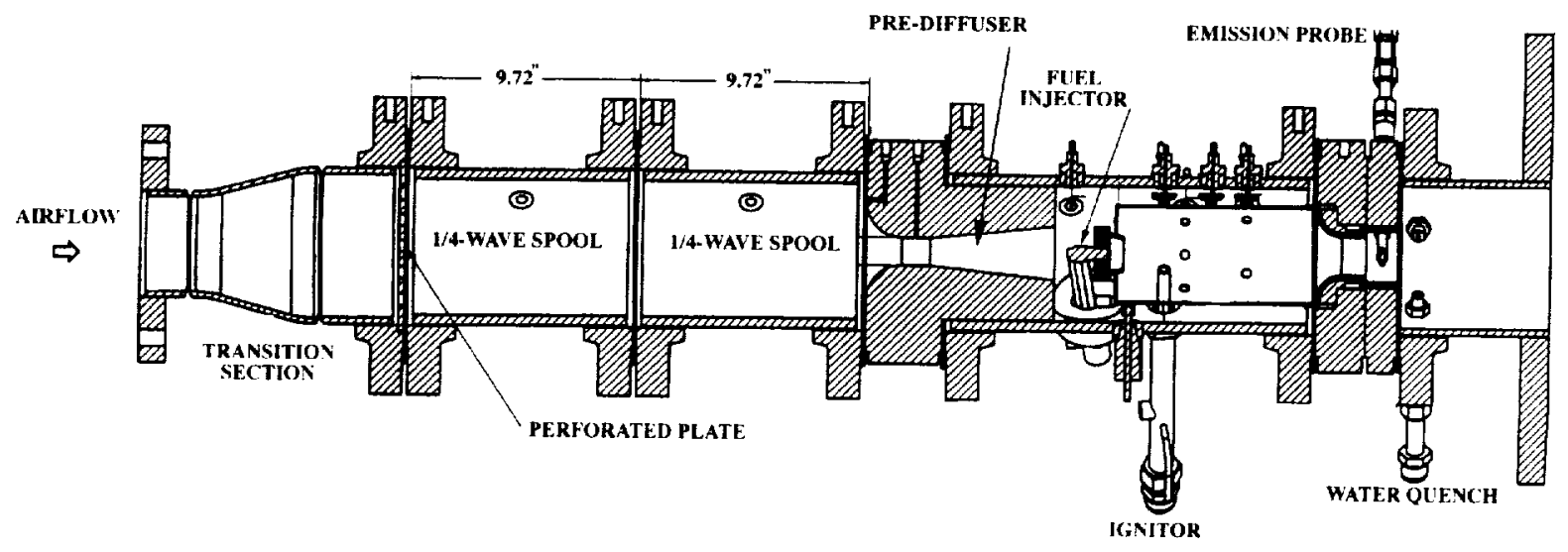

Figure 8 - Empirical Combustion Instability Control Rig Baseline Configuration

The single-nozzle combustor rig was operated in the baseline configuration shown in Figure 8 at pressures, temperatures, and fuel-air ratios corresponding to three different engine operating conditions. For the conditions corresponding to the mid-power condition chosen for evaluation $\left(\mathrm{T} 3=770^{\circ} \mathrm{F}\right.$, $P 3=200 p s i a$, fuel-air ratio $=0.03$ ), test results established the existence of a combustion instability at approximately $566 \mathrm{~Hz}$. The measured pressure spectrum inside the combustor at a location approximately 2 inches downstream of the fuel injector is shown in Figure 9. Pressure measurements at different axial locations and at the equivalent axial station but different circumferential locations showed this to be a longitudinal acoustic mode. This mode was also observed at the other two operating conditions, although at smaller amplitude and slightly lower frequencies.

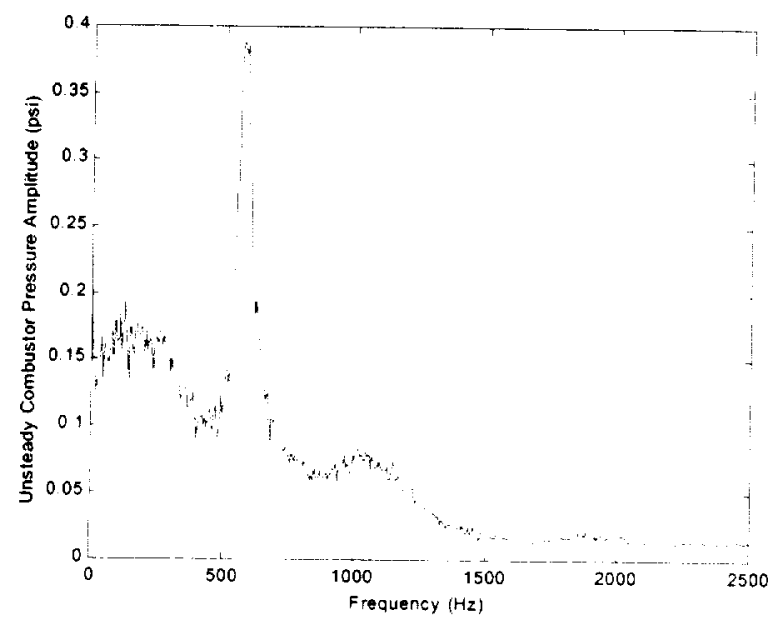

Figure 9 - Measured pressure spectrum of unsteady combustion pressure for the single nozzle combustor rig in the baseline configuration.
A comparison between the pressure spectrum in the engine and in the single-nozzle combustor rig at comparable operating conditions is shown in Figure 10. The combustor rig approximates the frequency and amplitude of the engine instability. However, the engine provides a narrower, more coherent frequency peak, and the rig exhibited a higher overall level of noise. $^{17}$

Overall, the single-nozzle rig provides a suitable test environment for combustion instability control research. A second phase of the empirical control effort has been initiated to develop a controller to suppress the observed combustion instability. Non-linear system identification and analytical models are guiding the development of reduced-order models of the research combustor. The reduced-order models will be used to develop control laws for experimental demonstration on the combustor rig.

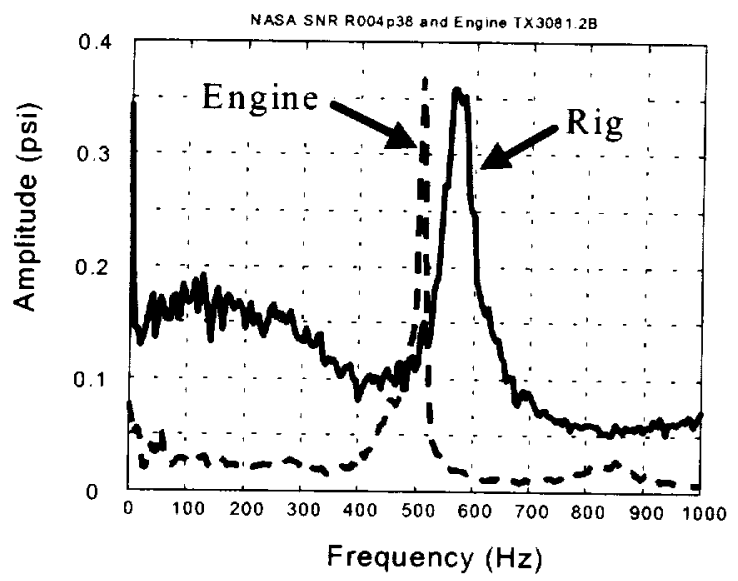

Figure 10 - Comparison of engine and baseline combustor rig pressure spectra 


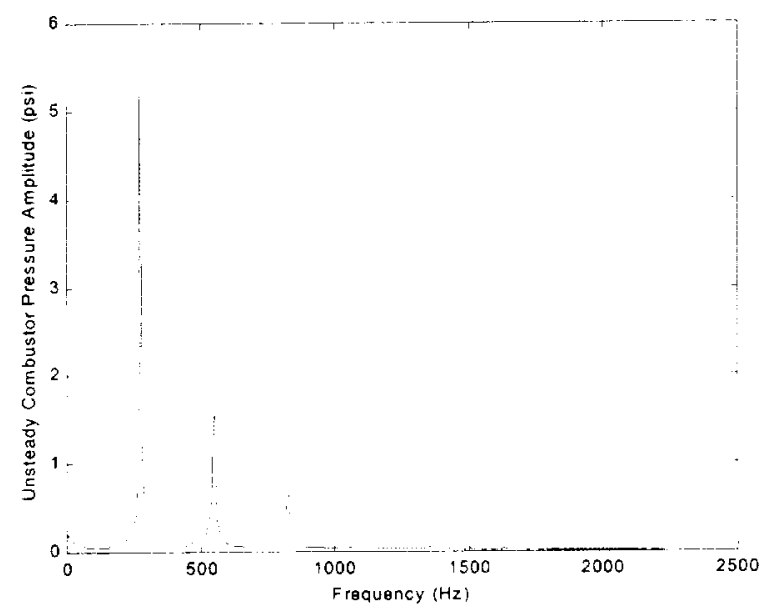

Figure 11 - Measured pressure spectrum of unsteady combustion pressure for the single-nozzle rig in the extended configuration

In addition to the baseline rig configuration shown in Figure 8, the combustor rig configuration was also changed to an extended configuration that placed the two 9.72 inch spool pieces between the pre-diffuser and the fuel injector. This extended configuration, when operated at the same mid-power evaluation condition as the baseline configuration, showed a dramatically different instability frequency $(273 \mathrm{~Hz})$ and magnitude (Figure 11). Higher order harmonics are evident, and the peaks here are narrow and coherent as compared with the results for the baseline configuration. ${ }^{18}$

The extended configuration also showed a certain "tune-ability", that is, the amplitude and the frequency of the instability varied considerably with operating condition and fuel-air ratio (Figure 12). This tendency to produce an instability of varying amplitude and frequency over a wide range of conditions seems to indicate that the extended configuration has the potential for producing instabilities for other nozzle/combustor configurations.

Physics-Based Combustion Instability Control The final activity in Combustion Instability Control utilizes an integrated systems approach toward physicsbased combustion control. Under a grant with Virginia Tech, methods are being investigated for increasing the physical understanding of combustion instabilities as they pertain to theoretical and test-based system models amenable to control. The end-goal of the effort is to develop more effective control strategies for combustion instability suppression. ${ }^{19,20}$ CFD and experimental studies have been conducted to support detailed analyses of the various physical mechanisms (fluid mechanics, chemical kinetics, acoustics, and heat
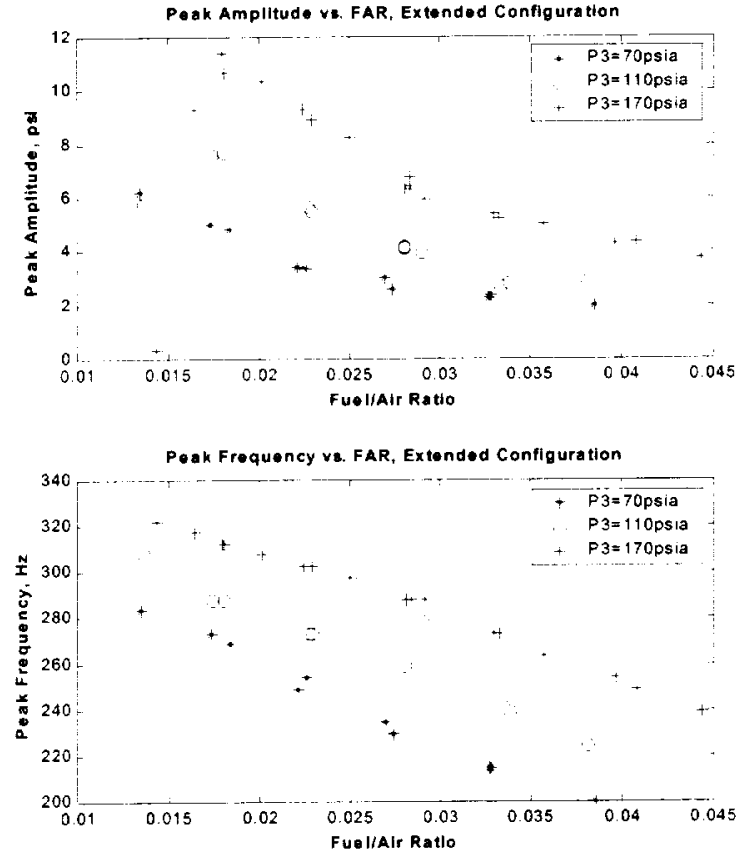

Figure 12 - Peak amplitude and peak frequency vs. fuel-air ratio for the extended configuration at three operating conditions

transfer) that underlie the inter-related phenomena observed during the occurrence of combustion instabilities. The roles of these various mechanisms have been studied for a simple laboratory tube combustor, which has been nonetheless a challenge to accurate theoretical, physics-based modeling efforts. This research has resulted in detailed characterization of: the laminar flame's dynamic response to acoustic perturbations, the interaction of thermo-diffusive and thermo-acoustic instabilities, and first-generation nonlinear models that can be used to estimate the frequency and amplitude of limit cycling behavior observed in the tube combustor.

The Virginia Tech research is also leading to better insight about techniques that produce reliable control of combustion instabilities. ${ }^{21.22}$ For example, this part of the effort recently provided analytical and experimental results that illustrate specific requirements for robust use of the least mean squares (LMS) adaptive signal processing algorithm in suppressing instabilities. ${ }^{23}$ The precise role of the system identification task required for compensation of the feedback in the reference signal has now been clearly shown and a robust implementation of the LMS controller has been demonstrated in simulation and experiments conducted on the tube combustor (Figure 13). ${ }^{23}$ Future work will address the use of adaptive control techniques on a dump combustor. 


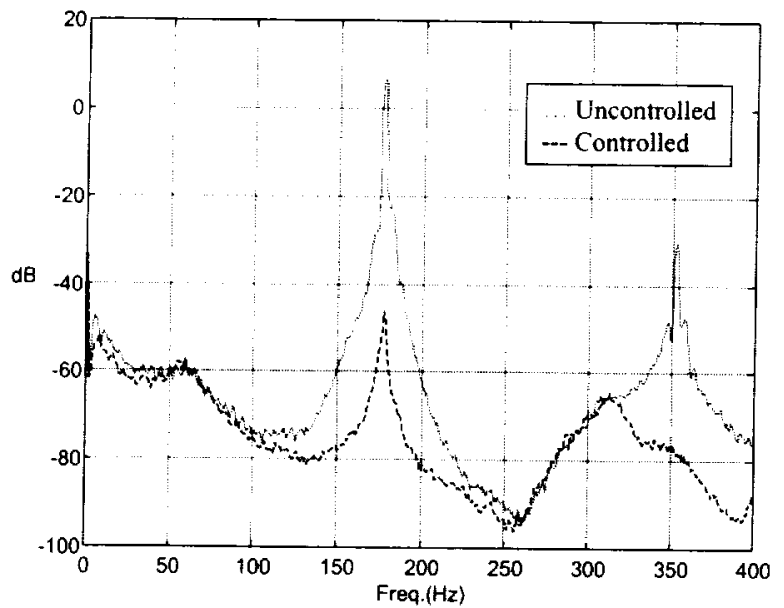

Figure 13 - Experimental data for a Rijke tube combustor operating at an equivalence ratio of about 0.51 and a total flow rate of $120 \mathrm{cc} / \mathrm{sec}$.

\section{Burner Pattern Factor Control}

The Burner Pattern Factor Control element seeks to develop an active engine fuel distribution system capable of producing a more uniform combustor exit temperature. The Active Pattern Factor Control (APFC) system architecture is shown in Figure 14. The APFC works in series with the primary fuel supply system. The fuel control system delivers the required total combustor fuel flow. Based on temperature feedback from circumferentially arranged temperature sensors at the combustor exit plane, the APFC issues commands to fuel flow modulators (valves) circumferentially arranged inside the combustor. The command signals dictate how these valves are to distribute the total fuel inside the combustor so as to achieve as uniform a temperature distribution at the exit plane as possible.

The pattern factor control work was performed by Honeywell Engines and Systems (formerly AlliedSignal Engines) under the NASA Advanced Subsonic Technology (AST) Program.

The highest risk element in this work was the development of thin film temperature sensors. A major effort was expended to develop thin-film type-S thermocouples that could be affixed to the backside surface of the turbine inlet stator vanes to provide the temperature feedback information needed by the APFC. A number of fabrication methods were investigated for the thin-film thermocouples and durability testing of the resulting thermocouples was conducted on base

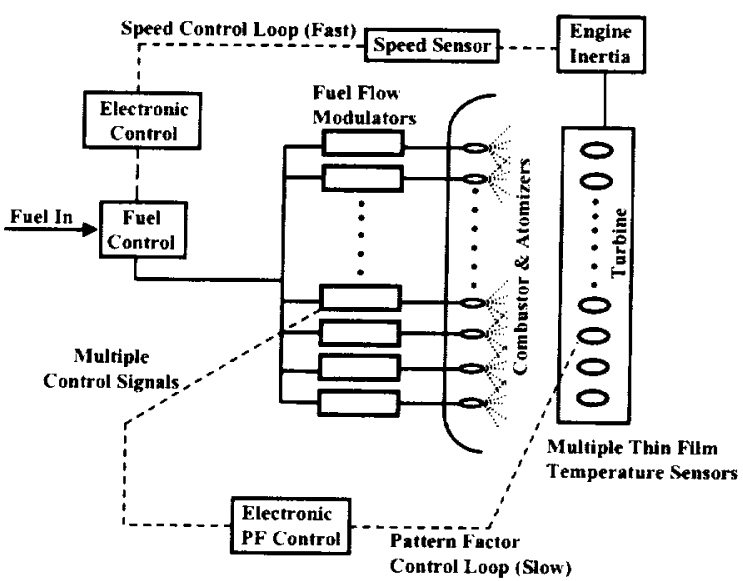

Figure 14 - Active Pattern Factor Control System Architecture

material prior to fabrication onto the turbine stators. Research was also conducted into determining a suitable method for affixing the sensors to the stators. ${ }^{24}$ The stator ring to be used in the rig tests was cut into 19 sectors (two vanes per sector) to fit into the thermocouple fabrication facility. A thin film sensor was then affixed to each of the 38 vanes. Figure 15 shows a photograph of an instrumented stator.

Specifications for the fuel flow modulators were determined and several candidates were examined. A downselect was made to use a Sturman Industries magnetically-latched solenoid valve typically used for small automotive diesel engines. The valve consists of a high-speed, pressure balanced spool and a hermetically sealed magnetic circuit. Residual magnetism provides a

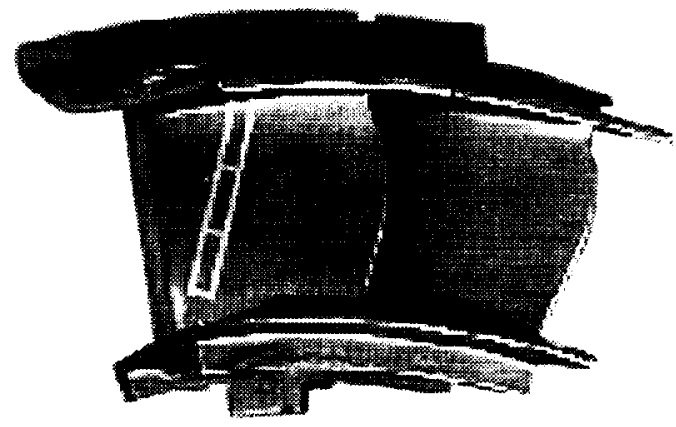

\section{Figure 15 - Thin-film thermocouple attached to a turbine stator vane}

(Photograph by Honeywell Engines and Systems) 
small holding or latching force that requires a brief, high current to switch but low current to hold in position. Simulation studies and hardware tests of the valves confirmed that the fuel distribution could be varied using pulse-width-modulation in response to sensed changes in exit temperature distribution. Bench testing revealed that a single valve influenced approximately a $20^{\circ}$ sector of the exit plane temperature profile, requiring a minimum of 18 circumferentially distributed valves. To provide a slight overlap, 19 valves were used.

Several control algorithms were evaluated for performing the APFC. From simulation evaluations it was decided to further investigate the performance of both a Proportional-Integral-Derivative (PID) and a fuzzy logic controller.

Two series of rig tests were performed. In the first series a significant number of the thin film sensors were damaged and the data collected were deemed questionable. Inspection of the sensors after the testing revealed lead wire splice failure as the primary failure mechanism. There was also some delamination of the thermocouple material. Valuable experience (in the form of lessons learned) was gained for furthering the development of this technology area.

In the second series of tests, the thin film sensors were replaced with conventional platinum-rhodium thermocouples. Two rig operating conditions (idle and medium power) were examined. Baseline measurements were taken without APFC for both of these conditions. For this effort, the pattern factor, $P F$, is defined as:

$$
P F=\frac{T_{P_{\text {eak }}}}{T_{\text {Alg }}}-1
$$

where $\mathrm{T}_{\text {Perk }}$ is the measured peak temperature at the combustor exit plane and $T_{\text {strg }}$ is the average measured temperature.

Preliminary testing showed the potential for pattern factor reduction with both the PID and fuzzy logic control techniques. For the idle condition, ( $\mathrm{T} 3=344^{\circ} \mathrm{F}, \quad \mathrm{P} 3=48 \mathrm{psia}$ ) the PID controller was successful in achieving a $47 \%$ reduction in pattern factor and a $7.3 \%$ reduction in NOx. It did, however, cause a $1.1 \%$ increase in $\mathrm{CO}$ and a $1.8 \%$ increase in UHC. The Fuzzy Logic controller achieved a $51.9 \%$ reduction in pattern factor and a $4.5 \%$ reduction in NOx; it caused an increase in $\mathrm{CO}$ of $1.0 \%$ and an increase in UHC of $1.3 \%$. For the medium power condition, ( $\mathrm{T} 3=707^{\circ} \mathrm{F}, \mathrm{P} 3=145 \mathrm{psia}$ ) the PID controller achieved a $30.8 \%$ reduction in pattern factor with a $1.4 \%$ reduction in NOx, a $0.04 \%$ reduction in $\mathrm{CO}$, and a $0.2 \%$ reduction in UHC. The Fuzzy Logic controller achieved a $42.5 \%$ reduction in pattern factor, a $1.3 \%$ reduction in NOx, a $0.08 \%$ increase in $\mathrm{CO}$, and a $0.62 \%$ increase in UHC. APFC data for the PID and Fuzzy controllers is shown in Figure 16.

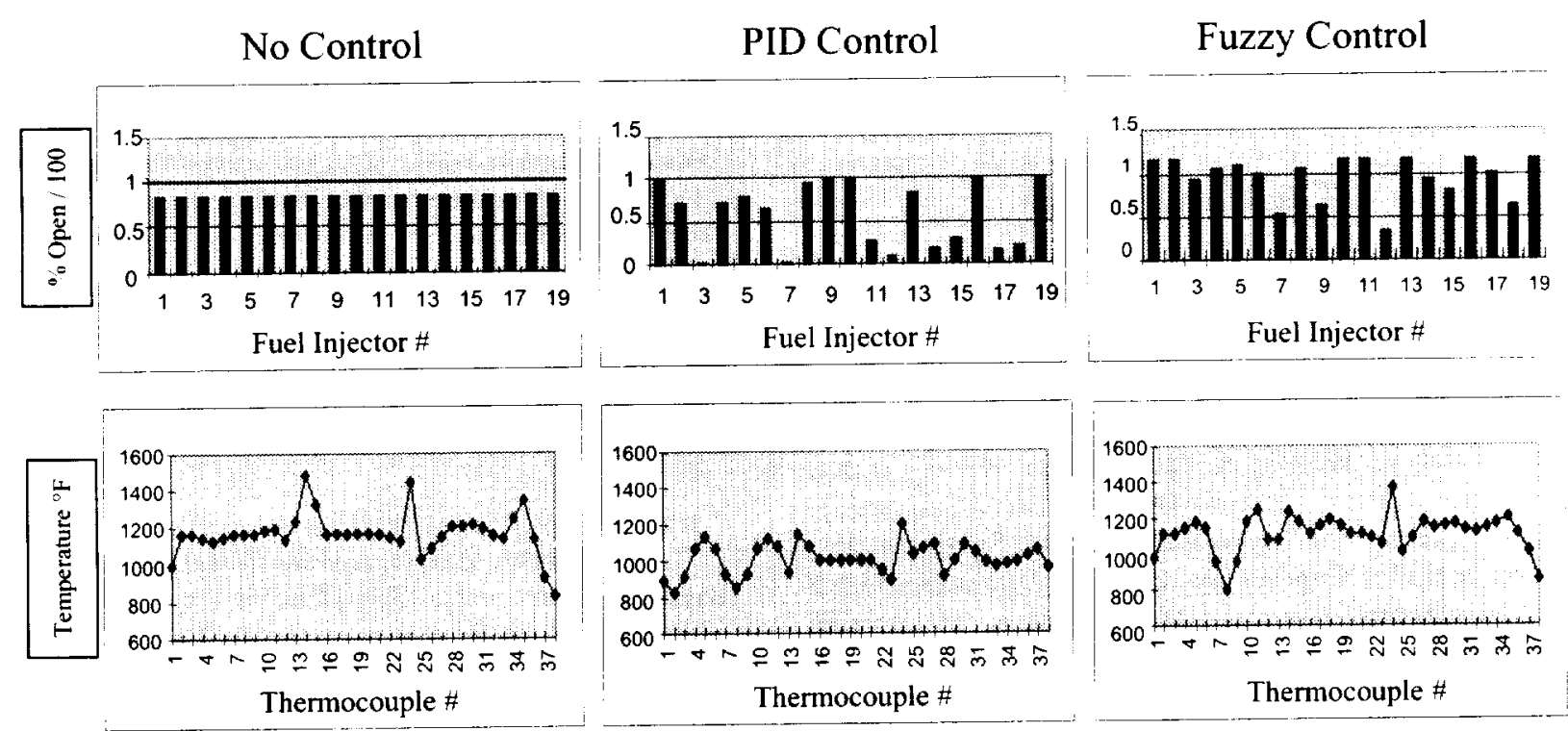

Figure 16 - Sample Active Pattern Factor Control results for the medium power condition. Steady-state performance of the PID and Fuzzy Controllers relative to the baseline uncontrolled case is shown. 


\section{Emission Minimizing Control}

The Emission Minimizing Control effort seeks to minimize emissions through active feedback control of fuel-air ratio. Combustors often incorporate fuel staging, that is, sequencing of the fuel injection through one or more local injection zones, in order to tailor the fuel-air mixture ratio over a large engine operating (airflow) range. Increased levels of staging allow increased resolution in the fuel-air mixture ratio. However, increased levels of staging also require increased valving to accomplish the staging.

Under the NASA AST Program, General Electric developed an intelligent fuel staging concept which includes a Control Pressure Fuel Nozzle (CPFN) along with model-based staging control. The CPFN provides a single pressure-driven linear actuator with multiple ports at each fuel injection station to selectively provide fuel to one or more fuel injection points. The modelbased staging control uses sensed combustor inlet pressure and temperature along with a calculated compressor airflow to estimate the emissions formation in order to determine when to sequence the injection points. The CPFN and model-based staging control have been successfully demonstrated on the GE control system test rig. This rig incorporates actual control system hardware with a simulated engine. Also under the NASA AST Program, GE developed a fuel multiplexer (FMUX) for more advanced engines incorporating even more levels of staging than would be practically supportable by the CPFN. The FMUX incorporates a rotating slotted cylinder to control the fuel to multiple injection locations. The FMUX has been fuel flow bench tested but has not been tested on the control system test rig.

\section{Concluding Remarks}

Early results from the NASA Glenn Research Center's Active Combustion Control Technology effort demonstrate the promise of active combustion control for aircraft gas turbine engines. The NASA Glenn effort is being conducted in partnership with academia and industry. Emphasis has been placed on engine relevance through experiments and analysis tied to aircraft gas turbine engine combustors. NASA Glenn's effort includes Combustion Instability Control, Burner Pattern Factor Control, and Emission Minimizing Control.

There are a number of technical challenges that must continue to be addressed in order for Active Combustion Control to become a reality for aircraft gas turbine engines. Temperature, emissions, and pressure sensors that can exist in the harsh environment in or near the combustor are needed as feedback devices for the controller. Highly-distributed fuel actuation, potentially employing micro-valving, is needed for precisely controlling fuel distribution. Fast, full authority fuel valves are needed for instability suppression. Accurate physics-based models of combustor dynamics continue to be required to guide the development of passive and active instability suppression methods. Simplified dynamic models are needed for controls development. And control methods are needed which provide or enhance the capabilities of combustors to achieve high performance and low emissions while maintaining full-envelope stability and operability margins.

The challenges to Combustion Instability Control, Burner Pattern Factor Control, and Emission Minimizing Control are being addressed in a somewhat synergistic fashion in the current NASA Glenn effort. However, in the future it is likely that a more closely coupled effort would result in a more efficient solution. NASA Glenn's long range vision is for the systems to implement instability control, pattern factor control, and emissions control be combined into a smart, fast, highly-distributed fuel-air management system. This would provide maximum flexibility to the designers of future combustors as they strive to meet the ever increasing performance and emissions demands placed on future engine systems.

\section{References}

'Lefebvre, A.H.: Gas Turbine Combustion, $2^{\text {nd }}$ edition, Taylor \& Francis, 1999.

2 Stubbs, R.M.; Liu, N.-S.: "Preview of the National Combustion Code," presented at the $33^{\text {rd }}$ Joint Propulsion Conference and Exhibit, Seattle, WA, July 1997, AIAA 97-3114.

${ }^{3}$ Liu, N.-S.; Quealy, A.: "NCC - A Multi-Disciplinary Design/Analysis tool for Combustion Systems," in proceedings of NASA Ames Research Center HPCP/CAS Workshop 98, NASA CP-1999-208757, January 1999.

\footnotetext{
${ }^{4}$ Yang, Z.; Breisacher, K.; Radhakrishnan, K.; Oyediran, O.: "Quick Stability Calculations for Longitudinal and Tangential Modes in Pre-Mixed Gas Turbine Combustors," Penn State Symposium on Propulsion, 1997.

${ }^{5}$ Peracchio, A.A.; Proscia, W.M.: "Nonlinear HeatRelease / Acoustic Model for Thermoacoustic Instability in Lean Premixed Combustors," presented at the International Gas Turbine \& Aeroengine Congress \& Exhibition, Stockholm, Sweden, June 1998, ASME Paper 98-GT-269.
} 
${ }^{6}$ Wang, S.; Hsiey, S.Y.: and Yang, V.: "Vortical Flow Dynamics and Acoustic Response of Swirl-Stabilized Injector," presented at $38^{\text {th }}$ Aerospace Sciences Meeting and Exhibit, January 2000, AIAA 2000-0434.

${ }^{7}$ Schadow, K.: Yang, V.: Culick, F.; Rosfjord, T.; Sturgess, G.; Zinn, B.: "Active Combustion Control for Propulsion Systems," AGARD Report 820, September 1997.

${ }^{8}$ Yu, K.; Wilson, K.J.; Schadow, K.C.: "Active Combustion Control in a Liquid-Fueled Dump Combustor," AIAA Paper 97-0462, January 1997.

"Zinn, B.T.; Neumeier, Y.: "An Overview of Active Control of Combustion Instabilities," AIAA Paper 97. 0461, January 1997.

${ }^{10}$ McManus, K.R.; Magill, J.C.; Miller, M.F.; Allen, M.G.: "Closed-Loop System for Stability Control In Gas Turbine Combustors," AIAA Paper 97-0463, January 1997.

1 Annaswamy, A.M.; El Rifai, O.M.; Fleifil, M.; Hathout, J.P.: Ghoniem, A.F.: "A Model-based Self-tuning Controller for Thermoacoustic Instability," in Combustion Science and Tech., Vol 135, pp. 213-240, 1998.

${ }^{12}$ Whitelaw, J.H.: "Combustion Oscillations, Extinction, and Control," final technical report, U.S. Army contract N68171-97-C-9035, May 1998.

${ }^{13}$ Hibshman, J.R.; Cohen, J.M.; Banaszuk, A.; Anderson, T.J.; Alholm, H.A.: "Active Control of Combustion Instability in a Liquid-Fueled Sector Combustor," presented at the International Gas Turbine \& Aeroengine Congress and Exhibition, June 1999, ASME Paper 99-GT215.

${ }^{14}$ McManus, K.R.; Poinsot, T.; Candel, S.M.: "A Review of Active Control of Combustion Instabilities," in Progress in Energy and Combustion Science, Volume 19. Issue 1, p. 1-29, February 1993.

${ }^{15}$ Paxson, D.E.: "A Sectored-One-Dimensional Model For Simulating Combustion Instabilities in Premix Combustors," presented at 38th AIAA Aerospace Sciences Meeting \& Exhibit, Reno, Nevada, January 2000, NASA TM 1999-209771, AIAA-2000-0313.

${ }^{16}$ KrishnaKumar, K.; Nishita, K.: "BORN - Bama Optimized Recurrent Neural Networks," Proceedings of the World Congress on Neural Networks, San Diego, CA, September 1996, p. 305-310.
${ }^{17}$ Cohen, J.M. et al: "Experimental Replication of an Aeroengine Combustion Instability," presented at ASME TurboExpo 2000, Munich, Germany, May 2000, ASME Paper 2000-GT-0093.

${ }^{18}$ Cohen, J.M. et al: "Longitudinal-Mode Combustion Instabilities: Modeling and Experiments," presented at the RTO Symposium on Active Control Technology,

Braunschweig, Germany, May 2000, NASA TM-2000210067.

${ }^{19}$ Saunders, W.R.; Vaudrey, M.A.; Eisenhower, B.A.; Vandsburger, U.; Fannin, C.A.: "Perspectives on Linear Compensator Designs for Active Combustion Control," presented at 37th AIAA Aerospace Sciences Meeting and Exhibit, Reno Nevada, January 1999, AIAA 99-0717.

${ }^{20}$ Fannin, C.A.; Saunders, W.R.; Vaudrey, M.A.; Eisenhower, B.A.; Vandsburger, U.: "Analytical and Practical Considerations for Control of Thermoacoustic Instabilities," presented at 37 th AIAA Aerospace Sciences Meeting and Exhibit, Reno, Nevada, January 1999, AlAA 99-0718.

${ }^{21}$ Vaudrey, M.A.; Saunders, W.R.; Eisenhower, B.: “A Test-Based Methodology For A Priori Selection of Gain/Phase Relationships in Proportional, Phase-Shifting Control of Combustion Instabilities," presented at the ASME TurboExpo 2000, Munich, Germany, May 2000, ASME Paper 2000-GT-530.

2 Vaudrey, M.A.; Saunders, W.R.; Baumann, W.T.: "Control of Combustor Instabilities Using An Artificial Neural Network," presented at the ASME TurboExpo 2000, Munich, Germany, May 2000, ASME Paper 2000GT-529.

23 Vaudrey, M.A.; Saunders, W.R.; Baumann, W.T.: "An Investigation of Adaptive Signal Processing Methods for Active Control of Combustion," presented at the RTO Symposium on Active Control Technology,

Braunschweig, Germany, May 2000.

${ }^{24}$ Niska, R.H.; Constant, A.P.; Witt, T.; Gregory, O.J.: "Chemical Vapor Deposition of Alpha Aluminum Oxide for High-Temperature Aerospace Sensors," presented at the American Vacuum Society $46^{\text {th }}$ International Symposium on Vacuum, Thin Films, Surfaces/Interfaces and Processing, Seattle, WA, October 1999, Paper AVS TF-TuA9. 


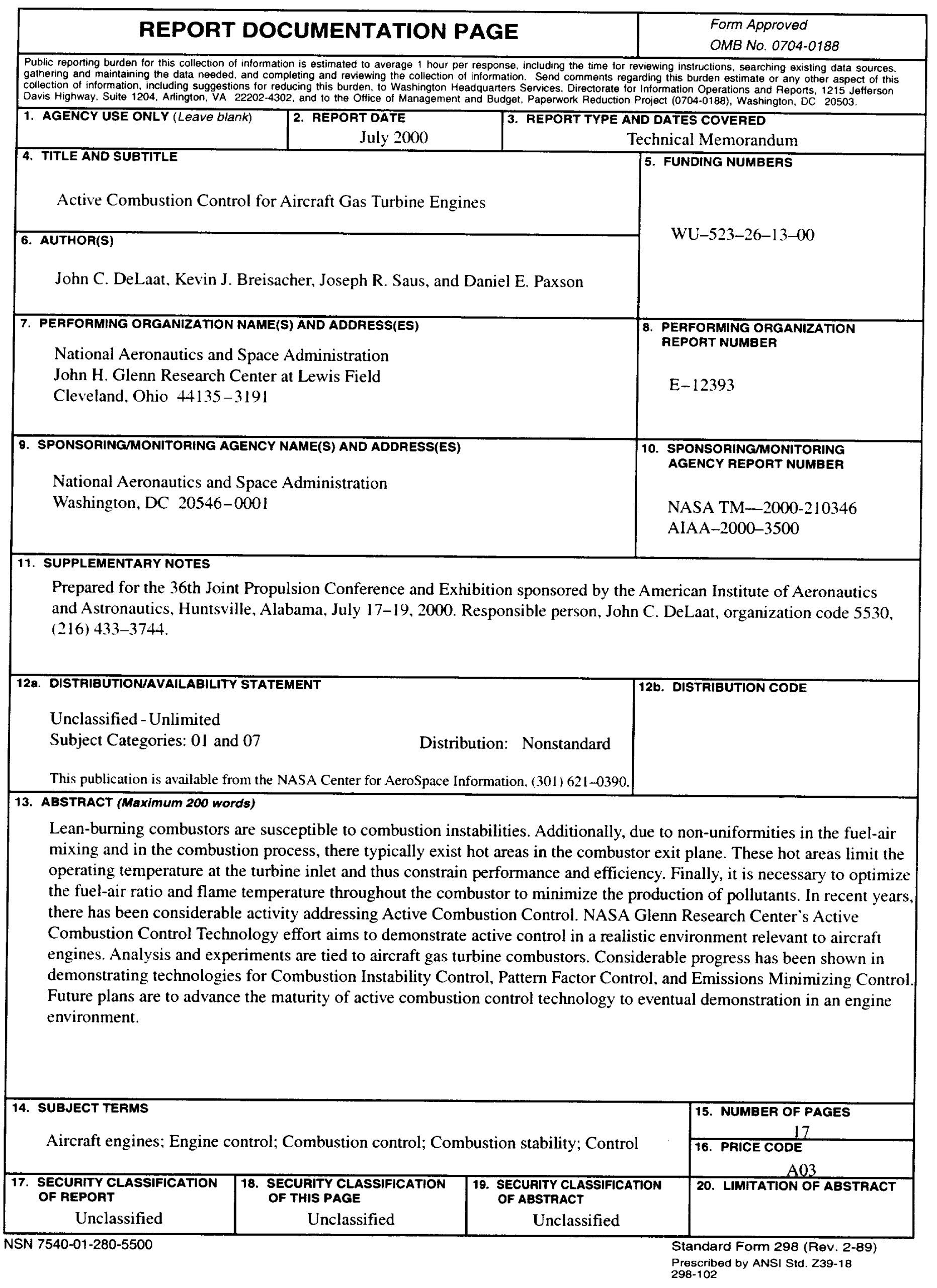





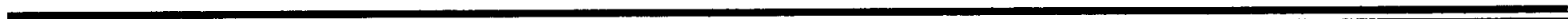

